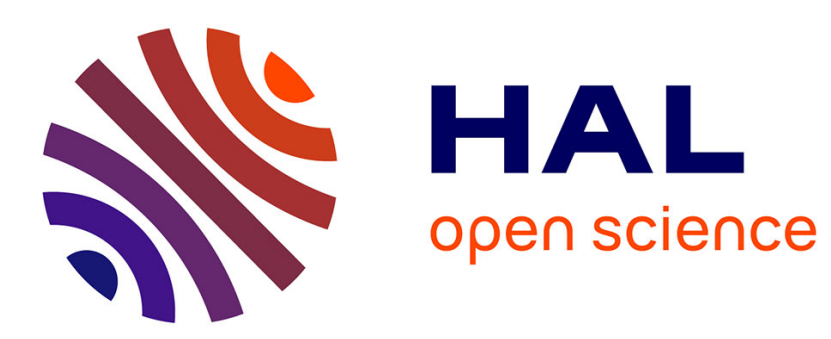

\title{
Solvent extraction of lithium from simulated shale gas produced water with a bifunctional ionic liquid
}

Guillaume Zante, Dominique Trébouet, Maria Yu Boltoeva

\section{To cite this version:}

Guillaume Zante, Dominique Trébouet, Maria Yu Boltoeva. Solvent extraction of lithium from simulated shale gas produced water with a bifunctional ionic liquid. Applied Geochemistry, 2020, 123, pp.104783. 10.1016/j.apgeochem.2020.104783 . hal-03419671

\section{HAL Id: hal-03419671 \\ https://hal.science/hal-03419671}

Submitted on 8 Nov 2021

HAL is a multi-disciplinary open access archive for the deposit and dissemination of scientific research documents, whether they are published or not. The documents may come from teaching and research institutions in France or abroad, or from public or private research centers.
L'archive ouverte pluridisciplinaire HAL, est destinée au dépôt et à la diffusion de documents scientifiques de niveau recherche, publiés ou non, émanant des établissements d'enseignement et de recherche français ou étrangers, des laboratoires publics ou privés. 
archives-ouvertes

\title{
Solvent extraction of lithium from simulated shale gas produced water with a bifunctional ionic liquid
}

\author{
Maria Boltoeva, Guillaume Zante, Dominique Trébouet
}

\section{To cite this version:}

Maria Boltoeva, Guillaume Zante, Dominique Trébouet. Solvent extraction of lithium from simulated shale gas produced water with a bifunctional ionic liquid. Applied Geochemistry, Elsevier, 2020, 123, pp.104783. 10.1016/j.apgeochem.2020.104783 . hal-03419671

\section{HAL Id: hal-03419671 \\ https://hal.archives-ouvertes.fr/hal-03419671}

Submitted on 8 Nov 2021

HAL is a multi-disciplinary open access archive for the deposit and dissemination of scientific research documents, whether they are published or not. The documents may come from teaching and research institutions in France or abroad, or from public or private research centers.
L'archive ouverte pluridisciplinaire HAL, est destinée au dépôt et à la diffusion de documents scientifiques de niveau recherche, publiés ou non, émanant des établissements d'enseignement et de recherche français ou étrangers, des laboratoires publics ou privés. 


\title{
Solvent extraction of lithium from simulated shale gas produced water with a bifunctional ionic liquid
}

\author{
Guillaume Zante ${ }^{a, b, *}$, Dominique Trébouet $^{a}$, Maria Boltoeva ${ }^{a}$ \\ a Université de Strasbourg, CNRS, IPHC UMR 7178, F-67000 Strasbourg, France \\ ${ }^{\mathrm{b}}$ ADEME, 20 Avenue du Grésillé, 49004 Angers Cédex 01, France \\ *Corresponding author \\ E-mail address: guillaume.zante@etu.unistra.fr
}

\begin{abstract}
The recovery of lithium from brines is a major field of study with an increase in lithium-ion batteries consumption and the subsequent growth of lithium consumption. The recovery of lithium from shale gas produced water is promising since these sources could contain nonnegligible concentrations of lithium. In this study, lithium extraction was investigated using solvent extraction with a bifunctional ionic liquid (IL) as an extracting agent diluted in $n$ dodecane. The components of these IL are cheap and commercially available products, namely Aliquat-336 (methyltrioctylammonium chloride) and DEHPA (di-(2ethylhexyl)phosphoric acid), and its synthesis is straightforward. Lithium extraction was optimized by studying several experimental parameters (mixing time, aqueous phase acidity, IL concentration in the solvent phase, aqueous lithium concentration). The mechanism of extraction was detailed, and the stripping was shown to be complete with $0.5 \mathrm{~mol} . \mathrm{L}^{-1}$ of $\mathrm{HCl}$. A two stages strategy was defined to recover lithium from synthetic brine. In the first stage, divalent metals are removed using five successive cycles of extraction with DEHPA ( 1 mol. $\left.\mathrm{L}^{-1}\right)$ dissolved in $n$-dodecane. In the second stage, the IL extracting agent [Aliquat-336][DEHPA] (1 mol. $\mathrm{L}^{-1}$ ) allowed to remove $83 \%$ of lithium in one cycle of extraction, which is higher than reported solvent extraction results with conventional extracting molecules.
\end{abstract}

Keywords: Lithium; Solvent extraction; Ionic liquid; Aliquat-336; DEHPA

\section{Introduction}

Lithium consumption increased abruptly in the last decade, mainly due to its utilization for the manufacture of rechargeable lithium-ion batteries. Consequently, many studies focused on the extraction of lithium from primary and secondary aqueous sources [1].

Many techniques were applied to achieve this goal, from membrane-based processes ([2]) and sorbent materials ([3]) to ion exchange resins [4]. To produce lithium-ion batteries, two main solid compounds are used, namely lithium hydroxide and lithium carbonate [5].

The precipitation of lithium carbonate from aqueous sources is frequently found in lithium production process [6], [7]. Using saturated sodium carbonate solutions, lithium carbonate solubility decreases with temperature, while sodium carbonate solubility increases, allowing to obtain solid lithium. However, the solubility of lithium carbonate is still relatively high 
even for high temperatures $\left(0.8 \mathrm{~g} \cdot \mathrm{L}^{-1}\right.$ at $\left.100^{\circ} \mathrm{C},[8]\right)$. Thus, techniques allowing the recovery of lithium from low concentrated aqueous solutions (containing less than $1 \mathrm{~g} . \mathrm{L}^{-1}$ of $\mathrm{Li}$ ) and its pre-concentration are needed.

This method is therefore unpractical for water resources containing low amounts of lithium such as brines or geothermal waters. Recently, brines obtained from shale oil and shale gas production have attracted attention. These brines contain non-negligible amounts of lithium (around $100 \mathrm{mg} . \mathrm{L}^{-1}$ ), together with alkaline-earth elements (around $10 \mathrm{~g} . \mathrm{L}^{-1}$ of calcium and around 1-2 g. $\mathrm{L}^{-1}$ of magnesium, strontium, and barium) and other alkalis (more than $20 \mathrm{~g} . \mathrm{L}^{-1}$ of sodium) [9], [10]. The recovery of the valuable metals could help reinforce the profitability of the installations but enlighten the need for robust and cheap recovery and separation techniques [11].

Solvent extraction has many advantages to extract metal ions such as low operational costs, high selectivity, and the possibility to treat low concentrated solutions [12]. Many works focused on the solvent extraction of lithium [13], [14], [15]. Despite the numerous solvent extraction systems developed recently, the extraction of lithium is still challenging, particularly due to its low oxidation state $(+1)$, high hydrophilicity and similar physicochemical properties than competing metal ions such as magnesium and sodium

The most efficient system is a synergistic system made of an acidic extractant (such as betadiketones and phosphoric acids) and a solvating reagent (tri-n-octylphosphine oxide is frequently used) [16], [17], [18], [19]. This system allows to extract lithium with a high selectivity towards other alkali metals. However, the extraction is possible when the acidic molecule is deprotonated, which requires alkaline $\mathrm{pH}$ in the aqueous phase.

To extract lithium from acidic aqueous solutions, one can use saponified organophosphorus extracting molecules, which make them able to treat acidic solutions [15]. However, the sodium salts of these extractants are somewhat soluble in water, which necessitates the costly treatment of wastewaters after the solvent extraction steps and leads to the production of large volumes of polluted waters [20].

Another well studied system is based on the addition of iron chloride and the extraction of the $\mathrm{LiFeCl}_{4}$ species by tri-butyl phosphate (TBP) alone or combined with organic synergists like methyl-isobutyl ketone, malonamides or di-(2-ethylhexyl) phosphoric acid (DEHPA) [21], [22], [23]. The extraction of iron chloride species allows to reach high selectivity for lithium towards magnesium and sodium, making this solution very convenient for the extraction of lithium from brines. However, the formation of the anionic $\mathrm{FeCl}_{4}^{-}$species is mandatory before lithium extraction, which requires a high concentration of chloride anion (>4 mol. $\mathrm{L}^{-1}$ ) and addition of hydrochloric acid. Thus, this system is only relevant if the aqueous phase contains a high chloride ion amount.

To avoid the addition of iron chloride, Shi et al. demonstrated the possibility to use TBP in combination with imidazolium-based ionic liquids [24], [25]. In this case, lithium is extracted by TBP by exchange with the ionic liquid cation, and the use of fluorinated hydrophobic 
anions helps to reinforce the extraction efficiency by allowing to form ion pairs with the extracted metal [26]. Despite some merits (extraction efficiency $>80 \%$, selectivity towards magnesium), the use of a fluorinated ionic liquid, as well as the cation exchange mechanism, is detrimental from the environmental point of view. The high cost of the ionic liquid and its physicochemical properties (high viscosity, hygroscopicity...) makes the large-scale application of this system difficult.

However, some ionic liquids (ILs) have interesting properties and can be useful for the design of relevant solvent extraction systems, such as non-fluorinated ionic liquids based on commercial extractants DEHPA or bis-(trimethylpentyl)phosphinic acid (HBTMPP; [27], [28]) as an anion. These ionic liquids were proven to be efficient and selective for lithium ions among other alkali metals. However, the method of synthesis of these ILs was based on a multistep strategy and used dichloromethane, which is unfavorable due to the toxicity of this molecular solvent.

In this work, our main objective is to design an affordable and simple solvent extraction system for the lithium ions with a bifunctional ionic liquid. The ionic liquid is made with cheap and available cation and anion, Aliquat-336 ([29]), and DEHPA, respectively. A simple and straightforward synthesis of this IL is used. Dodecane is selected as a diluent since it is a well-known and commonly used for solvent extraction. The solvent phase containing ionic liquid dissolved in the diluent fulfills the requirements of the current solvent extraction equipment (low viscosity, lower density than water...). In the second part of this work, we design a solvent extraction strategy to separate the valuable metals (alkaline earth metals and lithium) from a simulated brine obtained from shale gas production.

\section{Materials and methods}

\subsection{Reagents}

The ionic liquid methyl tri(octyl)ammonium chloride (Aliquat-336, purity> 97\%) was purchased from Sigma Aldrich. The extractant molecules, namely di-(2ethylhexyl)phosphoric acid (DEHPA, 95\%) was obtained from Alfa Aesar. The diluent $n$ dodecane (99\%) was obtained from Sigma Aldrich. The metal salts as well as hydrochloric acid were either purchased from Prolabo or Sigma Aldrich and are of the highest purity available. All of these chemicals were used as received. Deionized water $(18.2 \mathrm{M} \Omega . \mathrm{cm})$ is obtained with a Purelab Option Q apparatus.

\subsection{Preparation of the bi-functional ionic liquid}

The bi-functional ionic liquid is prepared according to the straightforward method described by Sastre et al. ([30], [31]). In brief, an equimolar mixture of Aliquat-336 and the extracting molecule are mixed in n-dodecane and vigorously shaken, allowing to form the ionic liquid. This organic mixture is then mixed several times with an aqueous solution of $\mathrm{NaHCO}_{3}(0.5$ mol. $\left.\mathrm{L}^{-1}\right)$, allowing to wash the hydrochloric acid formed during the reaction. These two steps can be presented by the following equations [31]: 
$\mathrm{NR}_{4} \mathrm{Cl}+\mathrm{HDEHPA} \leftrightarrow \mathrm{NR}_{4} \mathrm{ClHDEHPA}$

$\mathrm{NR}_{4} \mathrm{ClHDEHPA}+\mathrm{NaHCO}_{3} \leftrightarrow \mathrm{NR}_{4} \mathrm{DEHPA}+\mathrm{NaCl}+\mathrm{CO}_{2}+\mathrm{H}_{2} \mathrm{O}$

$\mathrm{NR}_{4} \mathrm{Cl}$ referring to the ionic liquid Aliquat-336, HDEHPA being the protonated form of the DEHPA molecule. The second step is repeated until all the excess chloride is washed from the organic phase, which is evidenced by the silver nitrate test. The organic phase is then repeatedly washed with water.

\subsection{Solvent extraction}

The exact mass of metal salt is weighed with a Sartorius BP 221S balance (precision \pm 0.01 $\mathrm{mg}$ ) and dissolved in deionized water to prepare the aqueous phase. The acidity of this solution is adjusted by adding aliquots of hydrochloric acid. The organic phase is made of extracting ionic liquid dissolved in dodecane. These two immiscible phases are then shaken at $1400 \mathrm{rpm}$ at $25^{\circ} \mathrm{C}$ with a Biosan TS-100 Thermoshaker apparatus, to promote phase mixing. The two phases are then centrifugated at $9500 \mathrm{rpm}$ for 2 minutes with a VWR Microstar apparatus to promote phase disengagement. The concentration of metal ions in the aqueous phase before $\left([M]_{\text {before }}\right)$ and after extraction $\left([M]_{\text {after }}\right)$ is determined by ICPOES with a Varian 720 ES apparatus. The distribution ratio for the metal $\left(D_{M}\right)$ is calculated with the following equation:

$\mathrm{D}=\frac{[M]_{\text {org }}}{[M]_{\text {aq }}} \times \frac{\text { Vorg }}{\text { Vaq }}=\frac{[M]_{\text {before }}-[M]_{\text {after }}}{[M]_{\text {after }}} \times \frac{\text { Vorg }}{\text { Vaq }}$

$[M]_{\text {org }}$ and $[M]_{a q}$ being the metal concentration in the organic and aqueous phase after extraction, respectively. Vorg and Vaq are the volume of an organic and aqueous phase, respectively. The organic to aqueous volume ratio is maintained at one in our trials unless otherwise stated. The distribution ratio values reflect the affinity of the metal for the organic phase and allow to estimate the extraction efficiency $(E, \%)$ :

$\mathrm{E}=\frac{D \frac{V_{\text {org }}}{V_{\text {aq }}}}{1+D \frac{V_{\text {org }}}{V_{\text {aq }}}} \times 100$

(4)

The stripping efficiency $(\mathrm{S}, \%)$ is calculated with the following equation [22]:

$\mathrm{S}=\frac{[M]_{\text {org }}-\left[M_{\text {org }, S}\right.}{[M]_{\text {org }}} \times 100$

(5)

Where $[M]_{\text {org }, s}$ is the concentration in the organic phase after stripping of the metal from the loaded organic phase.

\section{Results and discussion}




\subsection{Optimization of lithium extraction}

\subsubsection{Extraction parameters}

The effect of the mixing time on the distribution ratio values for the target metal is an important feature when using the solvent extraction technique. The results of the kinetics of lithium extraction with [Aliquat][DEHPA] ionic liquid dissolved in $n$-dodecane are reported in Fig. 1.

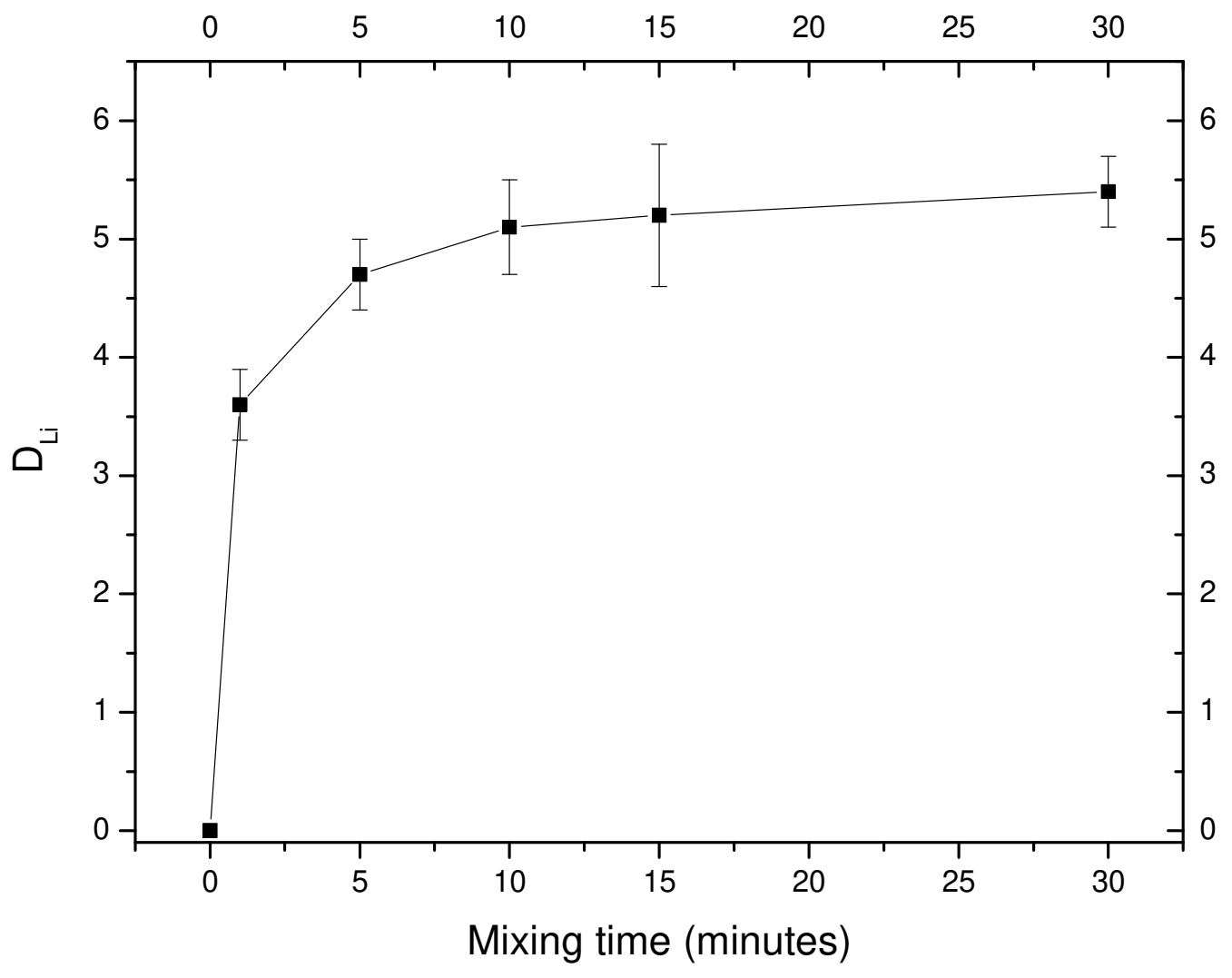

Figure 1. $D_{\mathrm{Li}}$ depending on the mixing time. Aqueous phase: $\mathrm{LiCl}\left(250 \mathrm{mg} \cdot \mathrm{L}^{-1}\right), \mathrm{pH}=5$. Organic phase: $\mathrm{LI}$ Aliquat-DEHPA (1 mol. $\left.\mathrm{L}^{-1}\right)$ diluted in dodecane. Lines are drawn for clarification purposes.

It can be seen that lithium distribution ratio is increasing in the first few minutes until it reaches a plateau for mixing times of ten minutes and longer. Thus, an equilibrium is reached with ten minutes of mixing. A mixing time of 30 minutes is retained for further experiments to ensure that the equilibrium is reached whatever the chemical conditions prevailing in the aqueous phase.

To prove the higher efficiency of the bi-functional [Aliquat][DEHPA] IL, it was compared with that of both its components, namely Aliquat-336 and DEHPA, used individually in the same diluent (Fig. 2). 


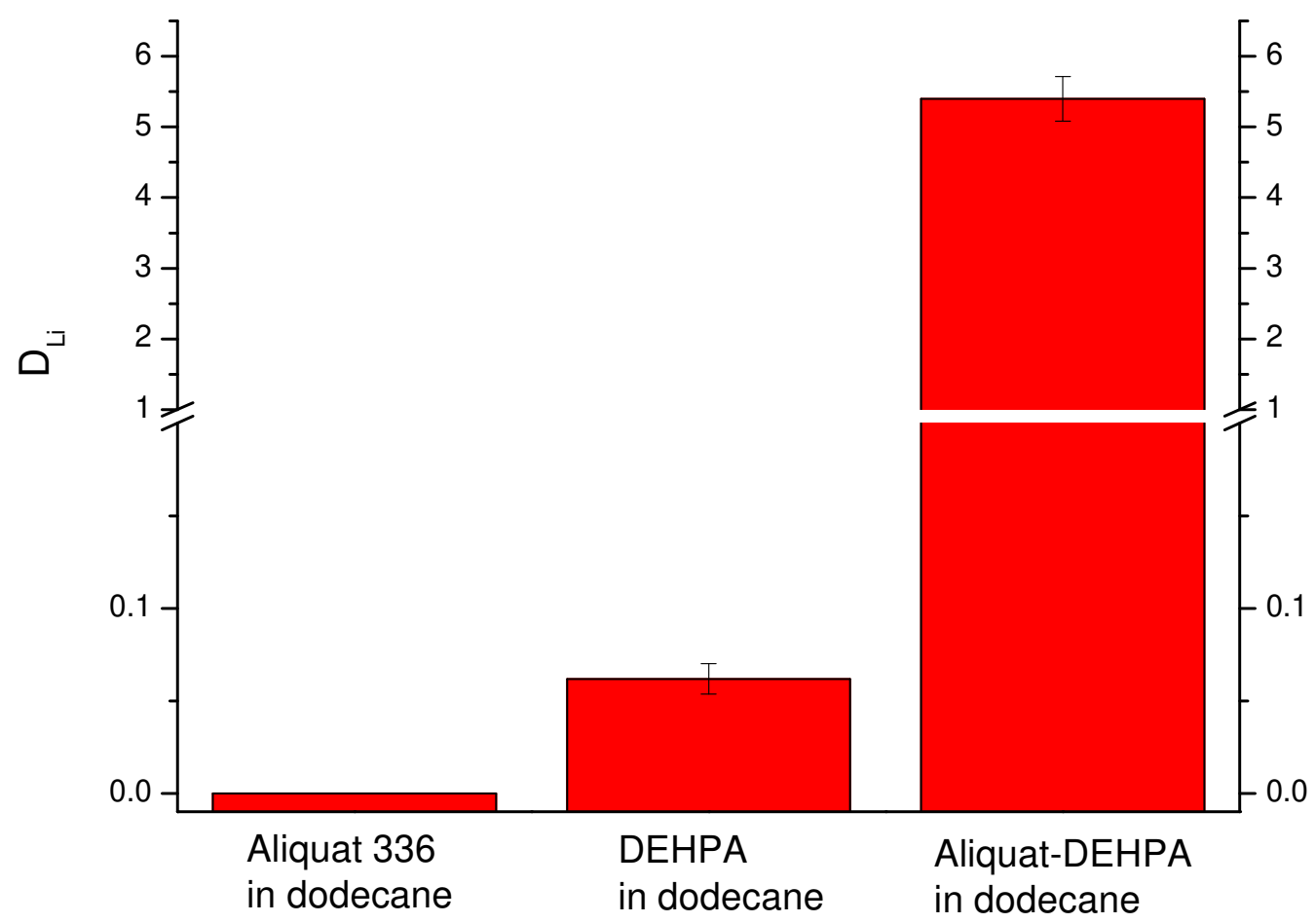

Figure 2. $D_{\mathrm{Li}}$ depending on the composition of the organic phase used. Aqueous phase: $\mathrm{LiCl}\left(250 \mathrm{mg} . \mathrm{L}^{-}\right.$ $\left.{ }^{1}\right), \mathrm{pH}=5$. Organic phase: 1 mol. $\mathrm{L}^{-1}$ of Aliquat-336 alone, DEHPA alone, or IL Aliquat-DEHPA diluted in dodecane. Lines are drawn for clarification purposes.

The distribution ratio values for lithium obtained with Aliquat-336 are negligible, which evidence that this extracting molecule has no affinity for the lithium ion. The distribution ratio values obtained with DEHPA alone are significant but remain low $\left(D_{\mathrm{L}}<0.1\right)$, which indicates that DEHPA can coordinate with the lithium ion [32], [19]. However, the acidic form of DEHPA is involved in the formation of dimers in the organic phase (Fig. 3) [33]. When the IL Aliquat-DEHPA is used as an extracting agent, DEHPA is under its ionized which reduces the hydrogen bonding ability and enhances its complexation ability towards the lithium ion ([27], [28]), thus leading to the inner synergistic effect [34]. As evidenced in Fig. 2, the distribution ratio for lithium is much higher when the IL Aliquat-DEHPA is used $\left(D_{L i}=5.4 \pm 0.3\right)$. Thus, the IL-based on DEHPA is much efficient than DEHPA alone and can be used without increasing the $\mathrm{pH}$ of the aqueous phase. The effect of the aqueous phase $\mathrm{pH}$ on the lithium extraction was investigated in Fig. 4. 


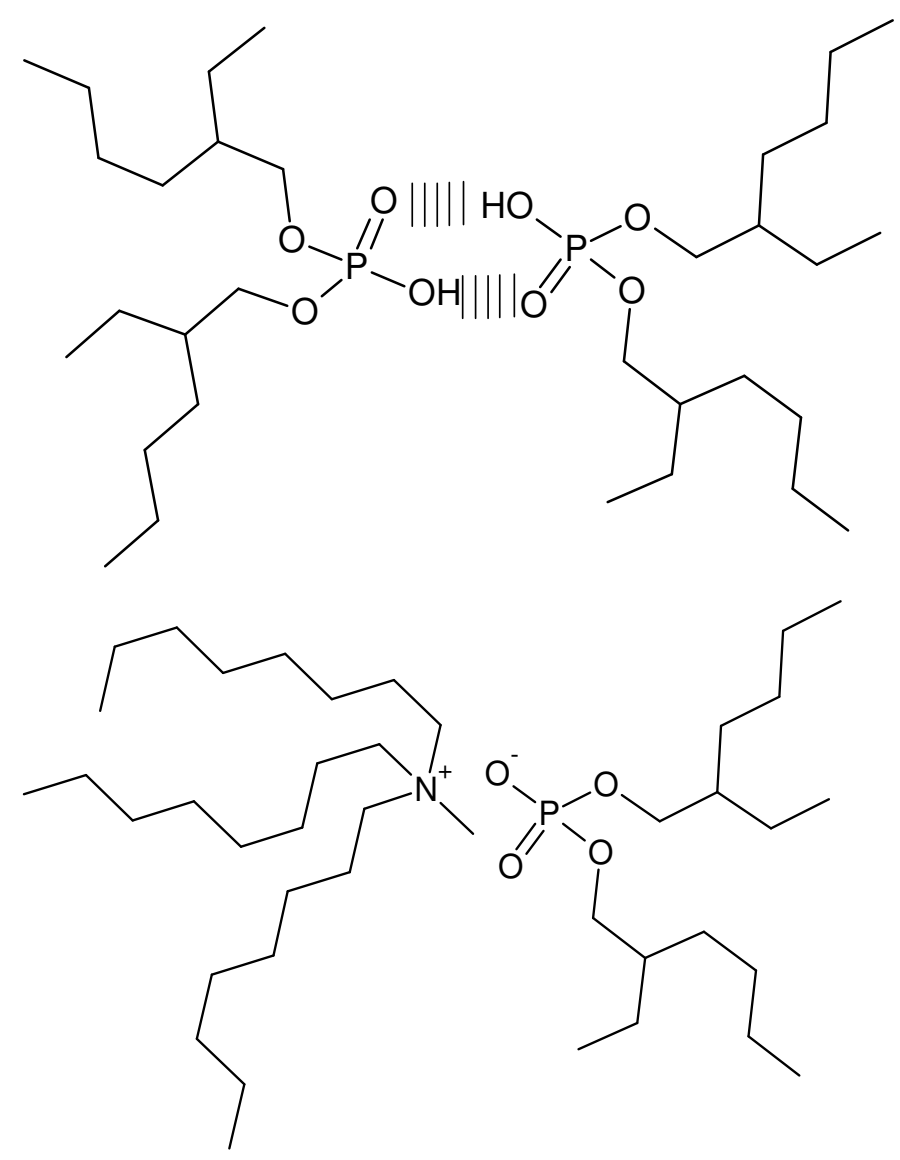

Figure 3. Dimeric structure of DEHPA (top) and structure of the ionic liquid Aliquat-DEHPA (down).

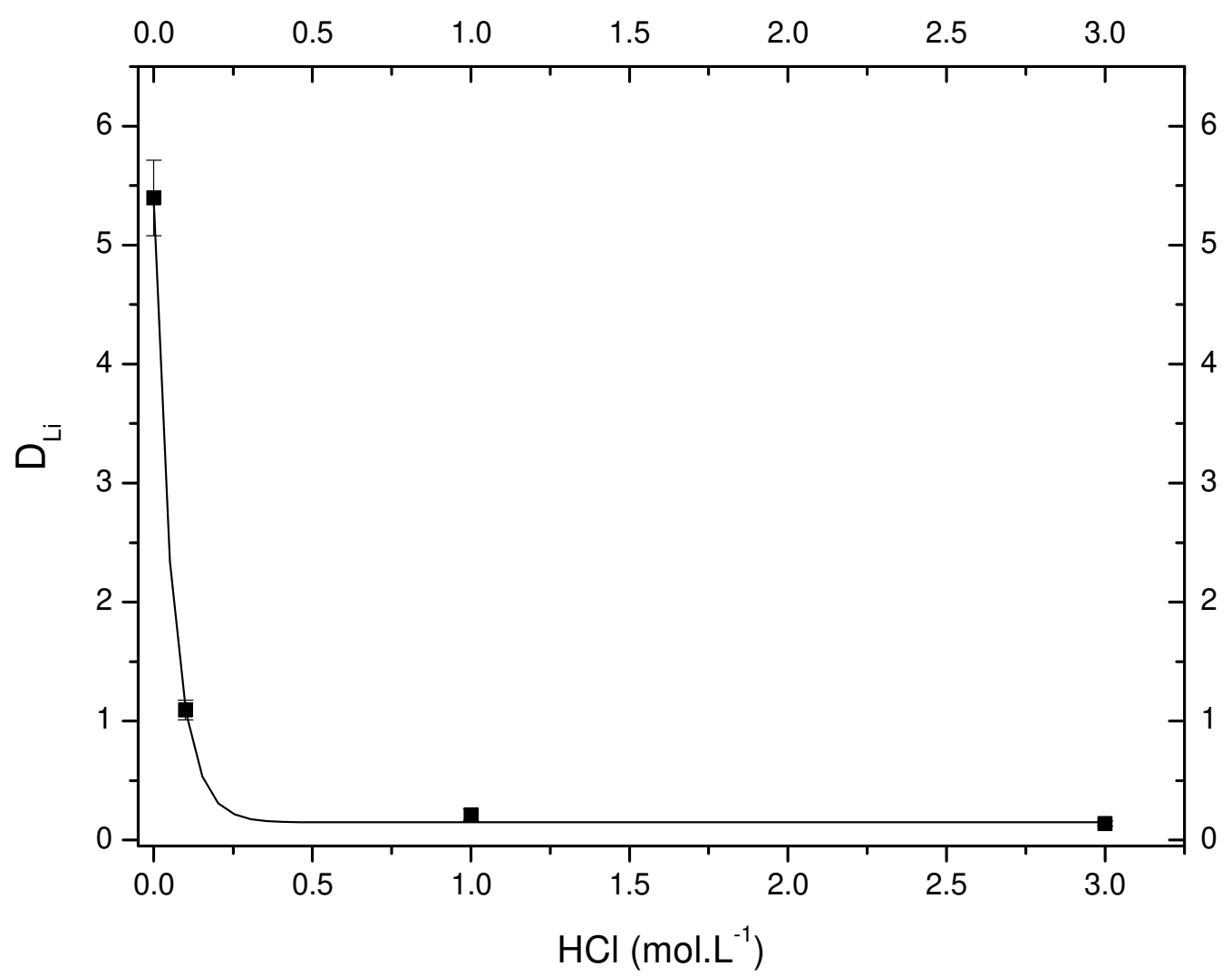

Figure 4. $\mathrm{D}_{\llcorner\mathrm{i}}$ depending on the hydrochloric acid concentration in the aqueous phase. Aqueous phase: 
LiCl (250 mg. $\left.\mathrm{L}^{-1}\right)$, pH variable. Organic phase: LI Aliquat-DEHPA (1 mol. $\left.\mathrm{L}^{-1}\right)$ diluted in dodecane. Lines are drawn for clarification purposes.

The higher distribution ratio is obtained without mineral acid in the aqueous phase. DEHPA is an acidic extractant which gets easily protonated, which can explain the trend of the decrease of the distribution ratio with the increase of acid content in the aqueous phase since protons are extracted more efficiently than lithium [27]. With $1 \mathrm{~mol}^{-\mathrm{L}^{-1}}$ of $\mathrm{HCl}$ or more in the aqueous phase, lithium extraction is almost negligible $\left(D_{\mathrm{Li}}<0.1\right)$. The acidity of the aqueous phase is a major feature of this solvent extraction system, but the extraction of lithium from low acidic or neutral solutions remains feasible.

The effect of the initial lithium concentration in the aqueous phase is also important and was investigated in Fig. 5.

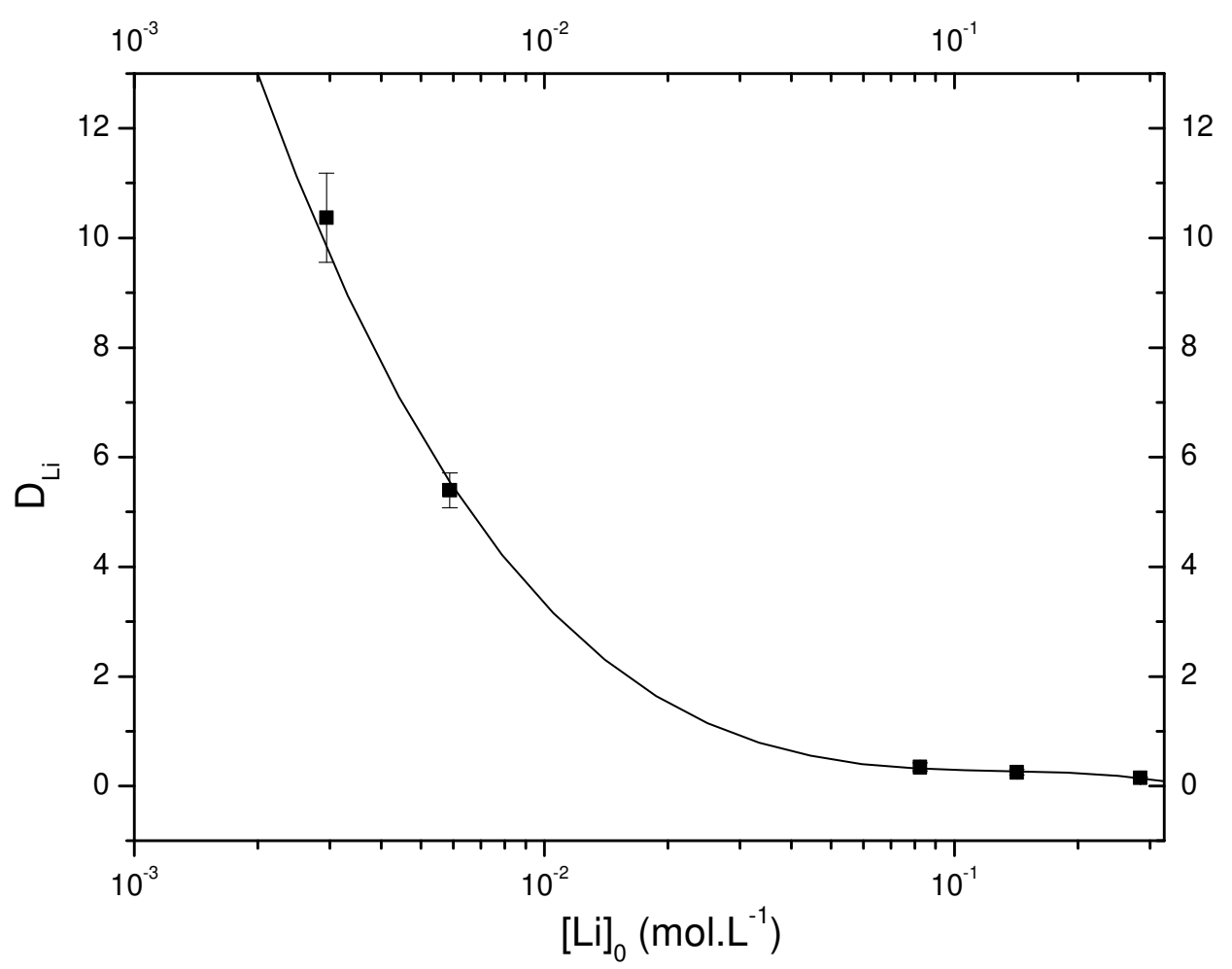

Figure 5. $\mathrm{D}_{\mathrm{Li}}$ depending on the lithium initial content in the aqueous phase. Aqueous phase: $\mathrm{LiCl}$ (variable), $\mathrm{pH}=5$. Organic phase: LI Aliquat-DEHPA $\left(1 \mathrm{~mol} . \mathrm{L}^{-1}\right)$ in dodecane. Lines are drawn for clarification purpose

It can be seen that the lithium distribution ratio is high when lithium concentration is low $\left(D_{\mathrm{Li}}>1\right.$ for $\left.[\mathrm{Li}]<10^{-2} \mathrm{~mol} . \mathrm{L}^{-1}\right)$. The lithium distribution ratio is gradually decreasing with an increase of initial lithium concentration in the aqueous phase, which could be explained by the loading capacity of the IL. Thus, this solvent extraction system is particularly indicated for low concentrated lithium solutions. 


\subsubsection{Mechanism of extraction}

The mechanism of extraction was investigated using the slope analysis method. It can be seen from Fig. 6 that the lithium distribution ratio values are increasing linearly by increasing the concentration of IL extracting agent in the organic phase.

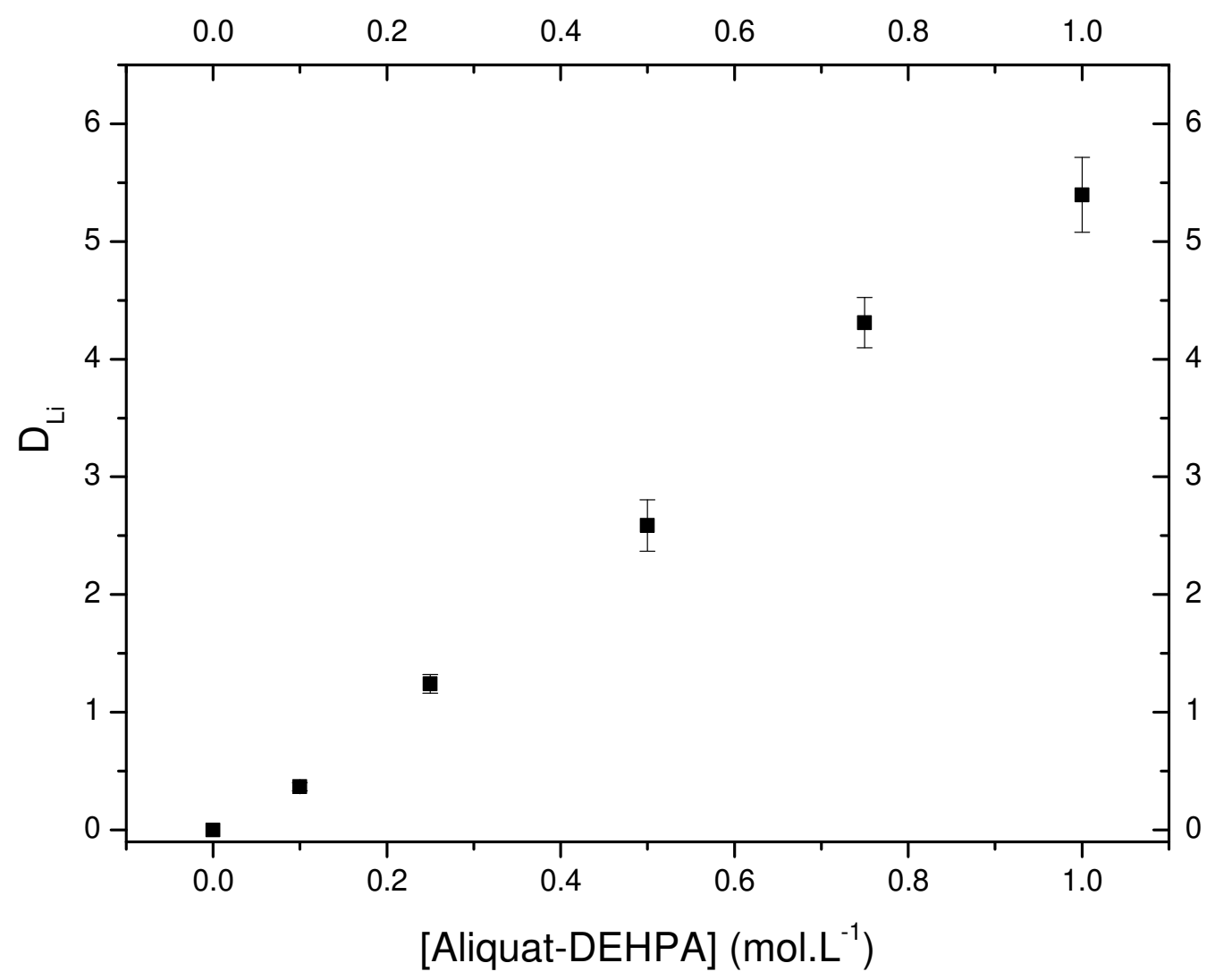

Figure 6. $D_{\mathrm{Li}}$ depending on the IL content on the organic phase. Aqueous phase: $\mathrm{LiCl}\left(250 \mathrm{mg} \cdot \mathrm{L}^{-1}\right)$, $\mathrm{pH}=5$. Organic phase: LI Aliquat-DEHPA (variable) diluted in dodecane.

The extraction of lithium by the bifunctionnal IL from the aqueous phase can be written as follows, assuming that DEHPA is responsible for the extraction of the lithium ion:

$L i_{a q}^{+}+n\left(D E H P A^{-}\right)_{o r g} \leftrightarrow\left(L i^{+} \bullet D E H P A_{n}^{-}\right)_{o r g}$

(6)

Where the subscripts "aq" and "org" refer to the aqueous and organic phase, respectively. DEHP The extraction constant $\left(K_{e x}\right)$ can be expressed as follows:

$K_{e x}=\frac{\left[L i^{+} \cdot D E H P A_{n}^{-}\right]_{o r g}}{\left[L i_{a q}^{+}\right]\left[D E H P A^{-}\right]_{o r g}^{n}}=\frac{D_{L i}}{\left[D E H P A^{-}\right]_{o r g}^{n}}$

(7)

The logarithmic expression of Eq. (7) gives:

$\log D_{L i}=\operatorname{nlog}\left[D E H P A^{-}\right]_{\text {org }}+\log K_{\text {ex }}$

(8) 
The variation of $\log D_{L i}$ as a function of $\log \left[D E H P A^{-}\right]_{\text {org }}$ is shown in Fig. 7. This plot should give a straight line, the value of the slope being " $n$ " (number of DEHPA molecules involved for the extraction of the lithium ion), and the intercept being the value of $\log K_{e x}$. It should be noticed that $\left[D E H P A^{-}\right]_{\text {org }}$ refers to the concentration of free $D E H P A^{-}$in the organic phase. Since the initial concentration of lithium in the aqueous phase is low, the free DEHPA concentration is considered as the same as the initial concentration of DEHPA introduced in the organic phase.

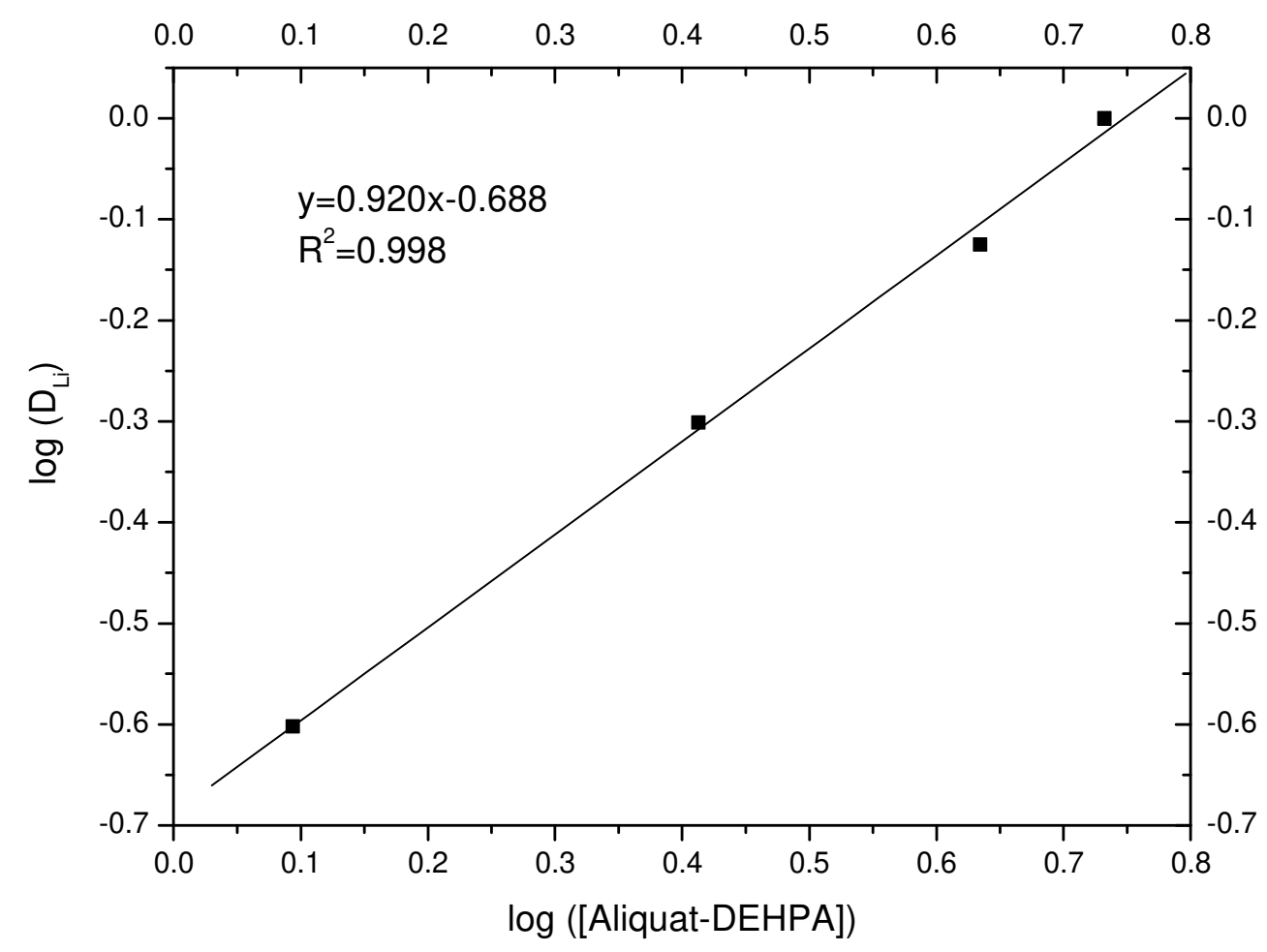

Figure 7. $\log D_{\mathrm{Li}}$ versus log [Aliquat-DEHPA]. Aqueous phase: $\mathrm{LiCl}\left(250 \mathrm{mg} . \mathrm{L}^{-1}\right), \mathrm{pH}=5$. Organic phase: $\mathrm{LI}$ Aliquat-DEHPA (variable) diluted in dodecane.

The plot given in Fig. 7 gives a slope approximately equal to one (0.920), indicating that one DEHPA molecule is involved in the extraction of lithium. The intercept value $(-0.688)$ allows to calculate the value of $\mathbf{K}_{\mathbf{e x}}$ which is estimated to be equal to 0.20. The mechanism of extraction does not involve an exchange of part of the ionic liquid with the extracted metal, which limits the contamination of the aqueous phase.

\subsubsection{Selectivity and stripping studies}

After extraction of the target metal, it has to be recovered from the loaded organic phase. This stripping step has to be efficient and advantageous with a low volume of the aqueous phase to reduce the consumption of mineral acid and water. According to Fig. 3, an acidic aqueous solution can be used to recover the metal in the aqueous phase. The amount of $\mathrm{Li}$ stripped $(S, \%)$ from the loaded organic phase is plotted in Fig. 8, for various concentrations of $\mathrm{HCl}$. 


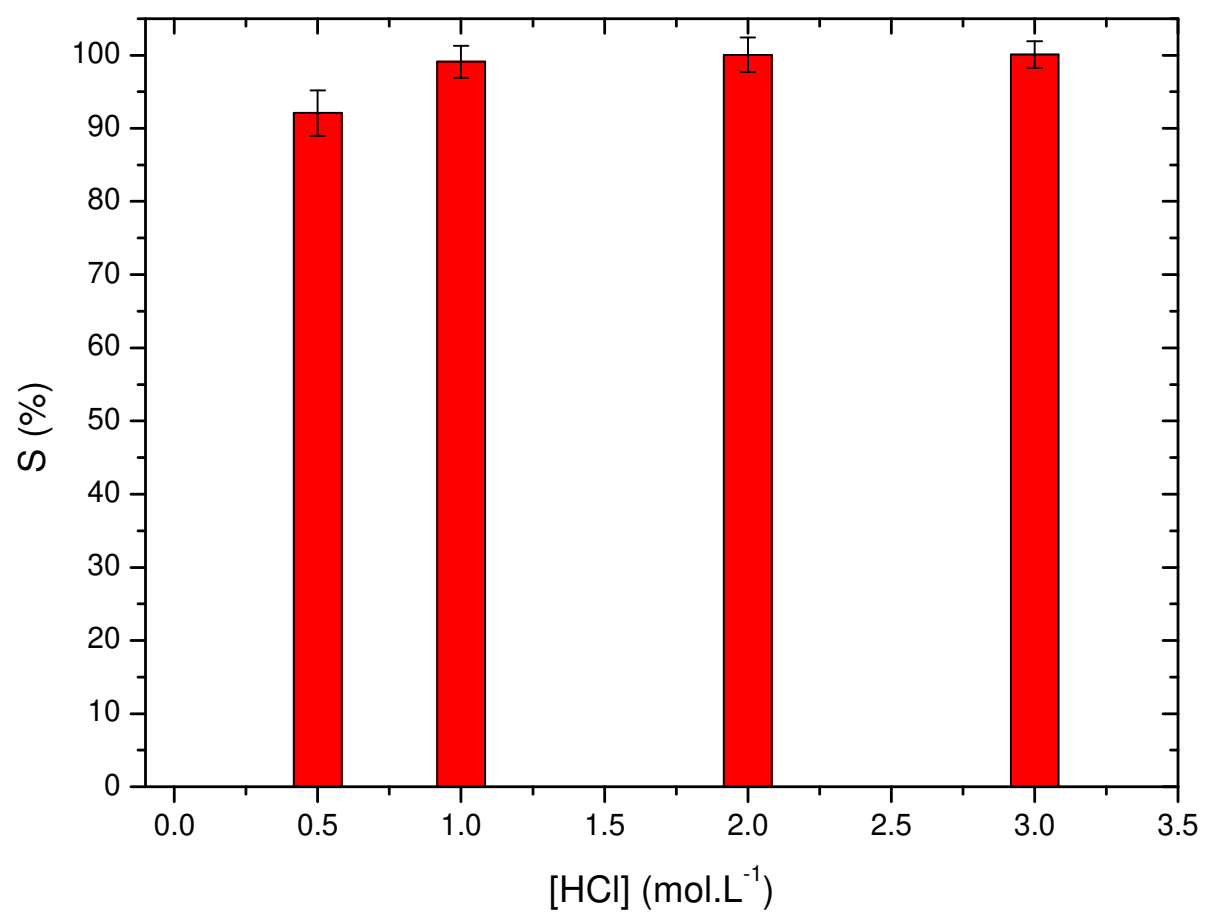

Figure 8. Amount of Li stripped from the loaded organic phase (1 mol. $\mathrm{L}^{-1} \mathrm{IL}$ in dodecane) depending on the aqueous $\mathrm{HCl}$ concentration. $\mathrm{O} / \mathrm{A}=2$

As evidenced in Fig. 4, protons compete with lithium ions in the organic phase for the DEHPA molecule. The stripping efficiency is higher with a high concentration of $\mathrm{HCl}$ in the aqueous phase. With a $\mathrm{HCl}$ concentration of $0.5 \mathrm{~mol}^{-\mathrm{L}^{-1}}$ a good stripping efficiency is obtained (92.1 $\pm 3.1 \%)$. The stripping is complete with a higher concentration of acid. For $\mathrm{HCl}=1 \mathrm{~mol} . \mathrm{L}^{-1}$ the stripping efficiency reaches $99.1 \pm 2.2 \%$. These parameters allow to limit the consumption of both water and acid since the organic to aqueous phase volume ratio is 2 .

The selectivity of the solvent extraction system was studied. Since the interaction between lithium and DEHPA is electrostatic by nature, the metals with the highest charge density will be extracted priorly, as shown in Fig. 9 where the distribution ratios of cobalt(II), nickel(II) and lithium(I) are compared. 


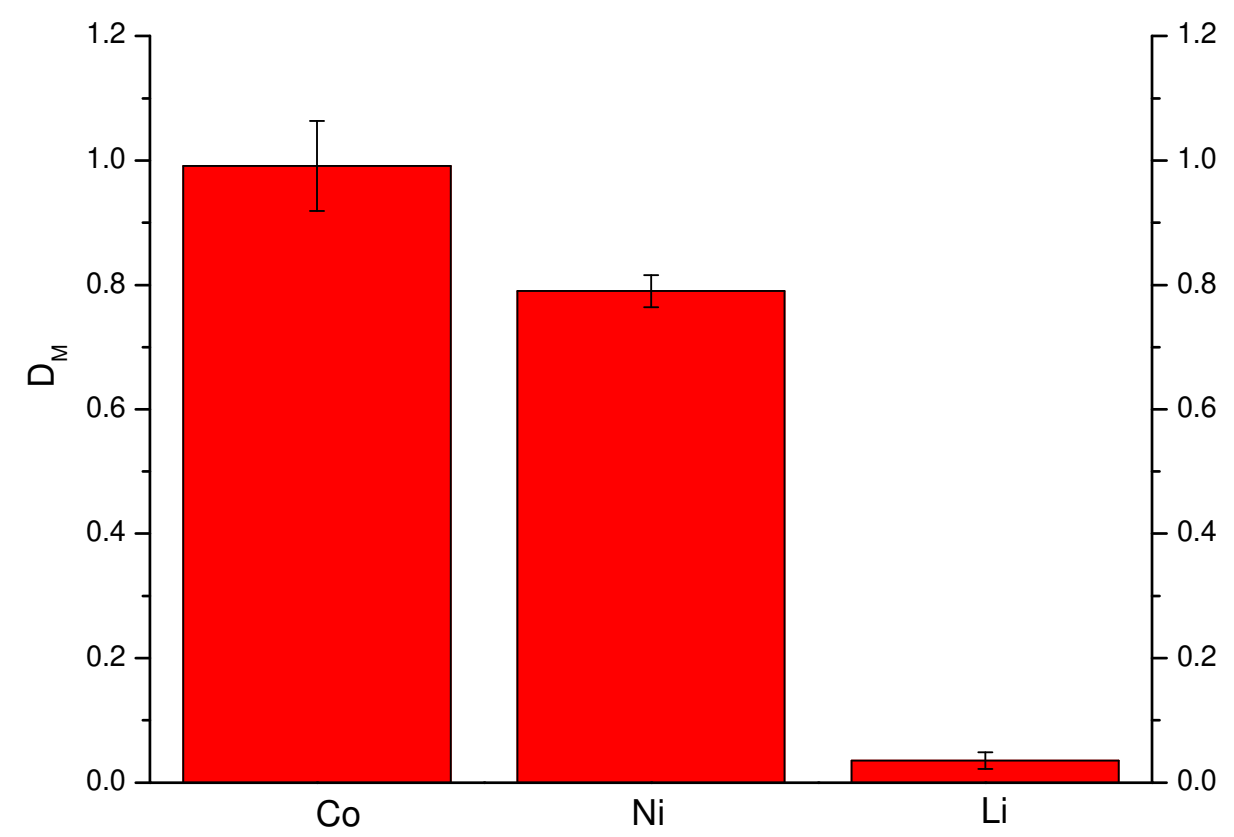

Figure 9. $\mathrm{D}_{\mathrm{Li}}, \mathrm{D}_{\mathrm{Co}}$ and $\mathrm{D}_{\mathrm{Ni}}$. Aqueous phase: $\mathrm{LiCl}, \mathrm{CoCl}_{2}$ and $\mathrm{NiCl}_{2}$ (250 mg. $\mathrm{L}^{-1}$ of each), $\mathrm{pH}=5$. Organic phase: IL Aliquat-DEHPA (1 mol.L-1 $)$ diluted in dodecane.

The distribution ratios of cobalt and nickel are higher than $D_{\mathrm{Li}}$, since DEHPA has a higher affinity for the divalent metals rather than the monovalent lithium ion. These divalent metals have a negative influence on lithium distribution ratio since lithium extraction is much lower when the aqueous phase is made of the three metals. Thus, the extraction of lithium from metals of higher valency is compromised, but this solvent extraction system can be used to separate lithium from metals with a lower charge density such as sodium (Table 1 ).

Table 1. $\mathrm{D}_{\mathrm{Li}}$ depending on the initial sodium/lithium molar ratio. Aqueous phase: $\mathrm{LiCl}$ and $\mathrm{NaCl}(250$ $\mathrm{mg} . \mathrm{L}^{-1}$ of Li, sodium variable), $\mathrm{pH}=5$. Organic phase: IL Aliquat-DEHPA (1 mol..-1 $)$ diluted in dodecane.

\begin{tabular}{cc}
\hline $\mathrm{Na} / \mathrm{Li}(\mathrm{mol} / \mathrm{mol})$ & $\mathrm{D}_{\mathrm{Li}}$ \\
\hline 0.1 & $3.2 \pm 0.4$ \\
1 & $1.7 \pm 0.2$ \\
2 & $1.0 \pm 0.1$ \\
\hline
\end{tabular}

Table 1 shows that the lithium distribution ratio is affected by the initial sodium content in the aqueous phase. $D_{L i}$ drops from $3.2 \pm 0.4$ to $1.0 \pm 0.1$ when the $\mathrm{Na} / \mathrm{Li}$ molar ratio is increased from 0.1 to 2 . Thus, the separation of these two elements is favorable and this solvent extraction system is particularly indicated for a solution containing low levels of lithium together with a high content of sodium. However, we observed an increase of the sodium content in the aqueous phase which could come from the excess sodium used for the synthesis of the IL. It is possible that part of DEHPA is saponified during the synthesis of the 
IL. This saponification leads to the release of $\mathrm{Na}^{+}$ions during the extraction of the metals [35]. The distribution ratios obtained for $\mathrm{Li}$ are much lower than those obtained with saponified DEHPA [14], and are closer to the distribution ratios obtained with bifunctional ILs [27], [28]. Neither emulsification nor volume variation was observed during the solvent extraction experiment. Thus, even if partial saponification cannot be neglected, the extraction of lithium is more likely related to the inner synergism of the IL.

\subsection{Solvent extraction scheme for the extraction of lithium from simulated brine}

\subsubsection{Removal of alkaline earth-elements}

A two-steps solvent extraction strategy was designed to recover lithium from a synthetic brine obtained after shale gas production. The $\mathrm{pH}$ value and chemical composition of the simulated brine studied in the present work are given below.

Table 2. Chemical composition and $\mathrm{pH}$ value of the synthetic brine used in this work compared to the properties of brines reported in the literature.

\begin{tabular}{cccc}
\hline Element & $\begin{array}{c}\text { Synthetic brine used in } \\
\text { this work, } \mathrm{mg} \cdot \mathrm{L}^{-1}\end{array}$ & $\begin{array}{c}\text { Synthetic produced water } \\
\text { studied in ref. [10], mg. } \mathrm{L}^{-1}\end{array}$ & $\begin{array}{c}\text { Synthetic brine used in } \\
\text { ref. [9], } \mathrm{mg} \cdot \mathrm{L}^{-1}\end{array}$ \\
\hline $\mathrm{pH}$ & 6.2 & $5.86-6.8$ & $5.6-6.3$ \\
$\mathrm{CaCO}_{3}$ & 0.3 & $7-8$ & - \\
$\mathrm{Ca}(\mathrm{II})$ & 480 & $10310-12710$ & $10985-11796$ \\
$\mathrm{Sr}(\mathrm{II})$ & 98 & $2301-2601$ & $2277-2412$ \\
$\mathrm{Ba}(\mathrm{II})$ & 78 & $1780-1924$ & $1825-1973$ \\
$\mathrm{Mg}(\mathrm{II})$ & 36 & $856-947$ & $869-919$ \\
$\mathrm{Li}(\mathrm{I})$ & 6 & $97.7-106$ & $90.7-98.1$ \\
$\mathrm{Na}(\mathrm{I})$ & 1230 & $24320-39780$ & $25868-27950$ \\
\hline
\end{tabular}

A typical brine contains large amounts of divalent cations and other metals. To reduce the number of extraction steps, a 25-fold dilution of the synthetic brine can be applied [10]. Before lithium extraction, the divalent metals have to be removed, which can be done with the DEHPA extractant alone, which is known to have a high affinity to these metals. The extraction efficiency for some alkaline-earth and alkali metals from the diluted brine with DEHPA diluted in dodecane is given in Fig. 10 over several cycles of extraction. 


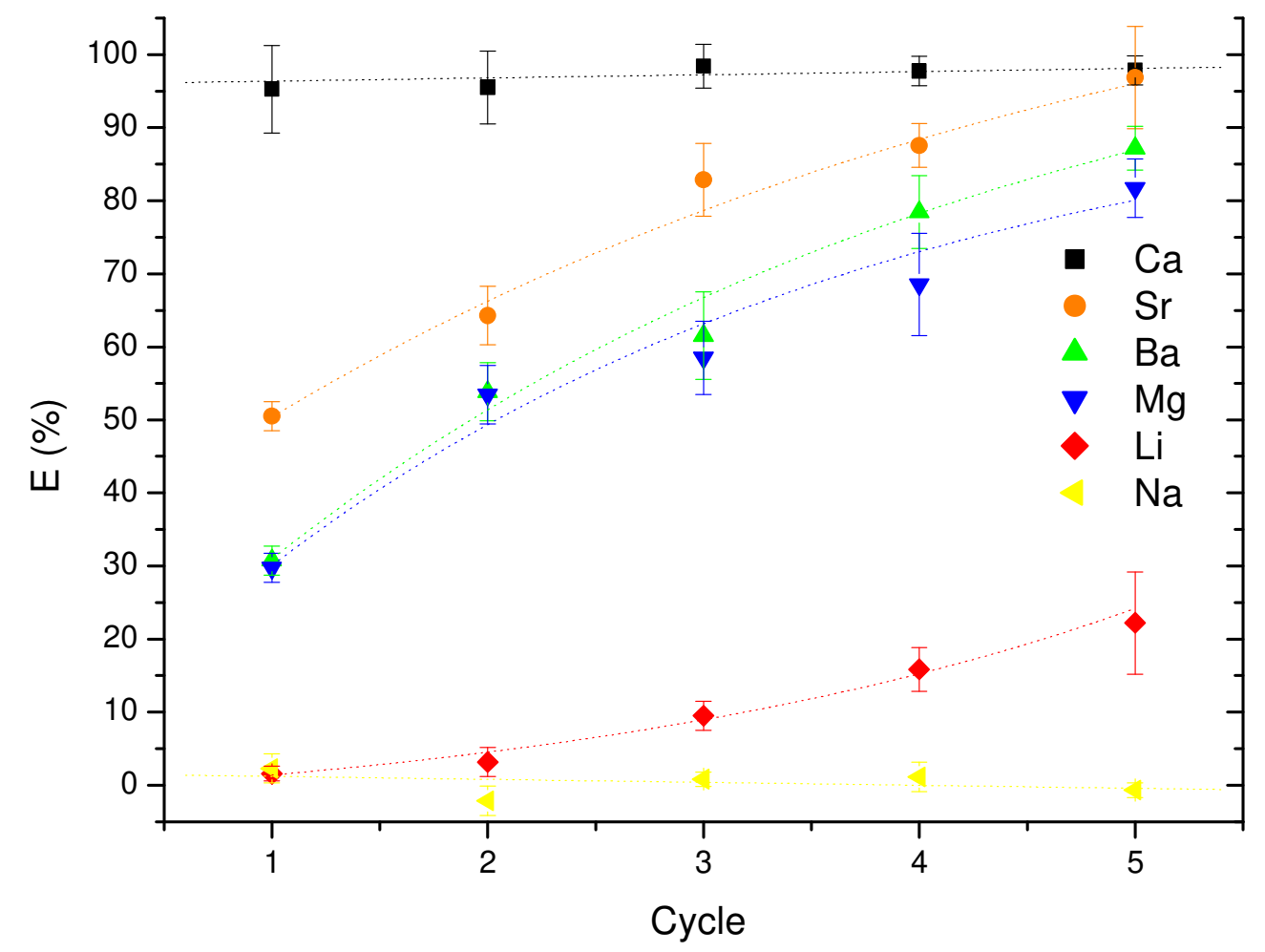

Figure 10. The extraction efficiency for several metals over several cycles of solvent extraction. Organic phase: DEHPA (1 mol. $\mathrm{L}^{-1}$ ) dissolved in dodecane. Aqueous phase: synthetic brine (see Table 1 for more details).

It can be seen from Fig. 10, most of the alkaline earth elements are removed from the synthetic brine with several cycles of extraction with DEHPA. The extraction selectivity order follows the trend $\mathrm{Ca}(\mathrm{II})>\mathrm{Sr}(\mathrm{II})>\mathrm{Ba}(\mathrm{II})>\mathrm{Mg}(\mathrm{II})>\mathrm{Li}(\mathrm{I})>\mathrm{Na}(\mathrm{I})$. Calcium is completely removed from the aqueous solution after the first step. The other metals required at least five consecutive extraction steps to be removed quantitatively. After 5 repetitions of extraction, more than $80 \%$ of $\mathrm{Sr}(\mathrm{II})$ and $\mathrm{Ba}(\mathrm{II})$ are extracted, and there are less than $10 \mathrm{mg} \cdot \mathrm{L}^{-1}$ of divalent elements left in the solution. Lithium mostly remains in the aqueous phase since $22 \pm 7 \%$ of lithium is extracted by DEHPA. No discernable amount of sodium is removed from the aqueous phase.

\subsubsection{Lithium separation from sodium}

Since the aqueous concentration of divalent metals is lower than $10 \mathrm{mg} \cdot \mathrm{L}^{-1}$, the further solvent extraction of lithium ions and the separation lithium-sodium with the IL [Aliquat][DEHPA] should be possible. The experimental results of the extraction for lithium and sodium ions depending on the IL [Aliquat][DEHPA] concentration in the solvent phase can be seen in Fig. 11. 


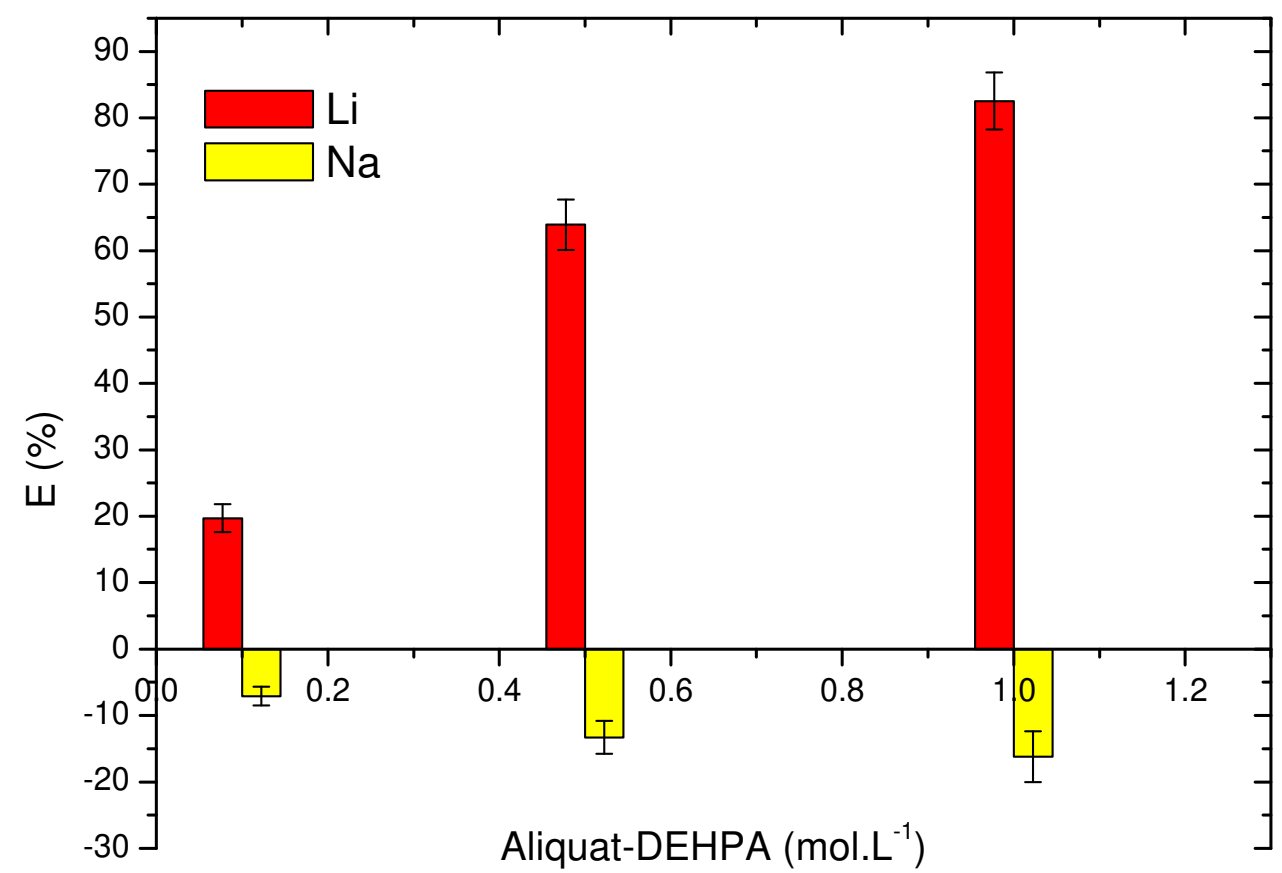

Figure 11. The extraction efficiency of lithium and sodium over several cycles of extraction. Organic phase: IL [Aliquat][DEHPA] (variable) dissolved in dodecane. Aqueous phase: Synthetic brine after the removal of alkaline-earths elements (see Table 2 and Fig. 11). $\mathrm{pH}=6.2$

The extraction of lithium is highly dependent on the concentration of IL extractant in the organic phase. The extraction efficiency of lithium is only $20 \pm 2 \%$ with $0.1 \mathrm{~mol}^{-L^{-1}}$ of IL in dodecane, and it reaches $83 \pm 4 \%$ with 1 mol. $\mathrm{L}^{-1}$ of IL. The extraction of sodium appears to be negative since sodium content increases in the aqueous phase due to the release of sodium ions from the organic phase. The presence of sodium is probably related to a partial saponification occurring during the synthesis of the IL, which could be avoided by using a different synthesis strategy [20]. The results obtained are compared with the literature data in the following table.

Table 3. Comparison of the results obtained in this work with literature data. TBP: Tri-butyl phosphate

\begin{tabular}{|c|c|c|c|}
\hline Aqueous phase & Organic phase & Results & Reference \\
\hline $\begin{array}{c}\text { Diluted }(\times 25) \\
\text { synthetic brine (see } \\
\text { Table 2) }\end{array}$ & $\begin{array}{l}\text { Aliquat-DEHPA IL (1 } \\
\text { mol. } \mathrm{L}^{-1} \text { ) in dodecane }\end{array}$ & $\begin{array}{l}83 \% \text { of Li extracted } \\
\text { in one cycle of } \\
\text { extraction }\end{array}$ & This work \\
\hline $\begin{array}{c}\text { Diluted (x25) } \\
\text { synthetic brine (see } \\
\text { Table 2) }\end{array}$ & $\begin{array}{l}\text { DEHPA }\left(1.5 \mathrm{~mol}^{-\mathrm{L}^{-1}}\right) \\
\text { and TBP }\left(0.3 \mathrm{~mol} . \mathrm{L}^{-1}\right) \\
\text { in kerosene }\end{array}$ & $\begin{array}{l}41 \% \text { of Li extracted } \\
\text { after } 10 \text { cycles of } \\
\text { extraction }\end{array}$ & [10] \\
\hline $\begin{array}{c}\text { Synthetic brine (see } \\
\text { Table 2) }\end{array}$ & $\begin{array}{l}\text { DEHPA }\left(1.5 \mathrm{~mol}^{-\mathrm{L}^{-1}}\right) \\
\text { and TBP }\left(0.3 \mathrm{~mol} . \mathrm{L}^{-1}\right) \\
\text { in kerosene }\end{array}$ & $\begin{array}{l}\text { Around } 40 \% \text { of } \mathrm{Li} \\
\text { extracted after } 8 \\
\text { cycles of extraction }\end{array}$ & [9] \\
\hline
\end{tabular}


The studies by Jang et al. and Lee et al. ([9], [10]) evidenced the synergism between DEHPA and TBP extractants diluted in kerosene for the extraction of lithium. However, the recovery rates are low, with around $40 \%$ of lithium extracted after several cycles of extraction. Using the Aliquat-DEHPA IL, $83 \%$ of Li could be recovered in only one cycle of extraction, after the removal of divalent elements. This performance could be due to the ionic character of the extracting agent which increases the extraction ability of DEHPA. However, Lee et al. showed that this kind of brines contained some organic compounds that could interfere with lithium extraction. One should pay attention to the presence of impurities other than metallic species that could interfere with lithium extraction. The hydrometallurgical scheme proposed for the recovery of lithium is given in Fig. 12.

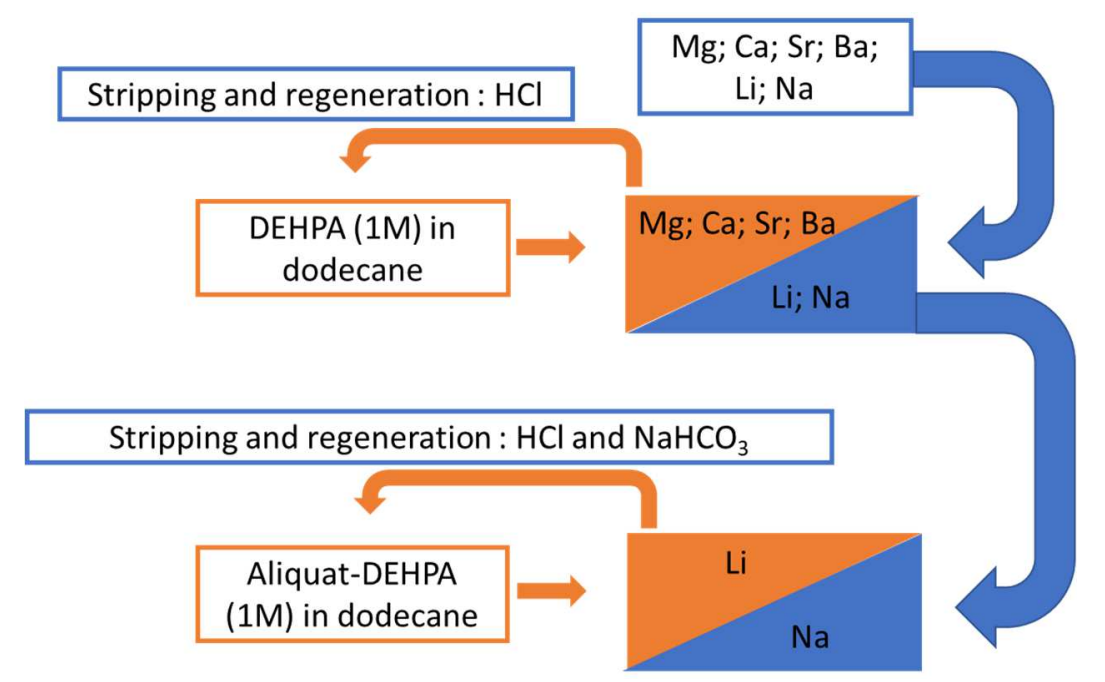

Figure 12. The hydrometallurgical scheme proposed for the recovery of lithium from shale gas produced water.

The proposed scheme consists of two stages of extraction. In the first stage, the divalent metals are removed by using several extraction cycles with DEHPA diluted in dodecane. At least 5 cycles are needed to remove more than $80 \%$ of $\mathrm{Mg}$ (II), $\mathrm{Ca}$ (II), $\mathrm{Sr}$ (II), and $\mathrm{Ba}$ (II) which could interfere during the lithium extraction stage. Then, metals can be stripped and DEHPA regenerated with acidic solutions. The separation of alkaline earth metals from each other could be interesting [36]. Less than $25 \%$ of lithium is removed during this first stage. On the second stage, lithium is separated from sodium using the IL [Aliquat][DEHPA], which allowed to extract $83 \%$ of lithium in one single cycle. Lithium can be then stripped by aqueous $\mathrm{HCl}$ solution and the IL extractant regenerated using $\mathrm{NaHCO}_{3}$.

\section{Conclusions}

The extraction of lithium from shale gas produced water was studied. The IL Aliquat-DEHPA was used since it can be made from cheap and commercially available products with a straightforward synthesis. The experimental parameters affecting lithium extraction were detailed. Low acidity and sufficiently high IL extractant content is mandatory to provide efficient lithium extraction. The underlying mechanism of extraction was outlined, and it was 
showed that extraction occurs via coordination of DEHPA to the lithium ion. The presence of divalent metals, as well as sodium, reduces lithium extraction efficiency. However, lithium extraction from low concentrated solutions and its separation from sodium is feasible. A two-stage strategy was used to recover lithium from synthetic shale gas produced water. In the first stage, the divalent metals were removed using DEHPA. 5 successive cycles are needed to remove at least $80 \%$ of the divalent metals. In the second stage, lithium is extracted with the Aliquat-DEHPA IL. While DEHPA alone can extract $40 \%$ of lithium after 10 cycles of extraction, $83 \%$ of lithium can be recovered in one step with the IL. The brine has to be diluted but no modification of the $\mathrm{pH}$ is required, and the mechanism of extraction does not lead to contamination of the aqueous phase, which could avoid costly wastewater treatment after solvent extraction.

\section{Acknowledgments}

The financial support from the French Environment \& Energy Management Agency (Agence de l'Environnement et de la Maîtrise de l'Énergie, ADEME, PhD fellowship to GZ) is gratefully acknowledged. The authors thank Dr A. Boos, P. Ronot and I. El-Masoudi (IPHC, France) for the ICP-OES analysis.

\section{References}

[1] B. Swain, Recovery and recycling of lithium: A review, Separation and Purification Technology. 172 (2017) 388-403. https://doi.org/10.1016/j.seppur.2016.08.031.

[2] X. Li, Y. Mo, W. Qing, S. Shao, C.Y. Tang, J. Li, Membrane-based technologies for lithium recovery from water lithium resources: A review, Journal of Membrane Science. 591 (2019) 117317. https://doi.org/10.1016/j.memsci.2019.117317.

[3] Q.-H. Zhang, S. Sun, S. Li, H. Jiang, J.-G. Yu, Adsorption of lithium ions on novel nanocrystal MnO2, Chemical Engineering Science. 62 (2007) 4869-4874. https://doi.org/10.1016/j.ces.2007.01.016.

[4] F. Arroyo, J. Morillo, J. Usero, D. Rosado, H. El Bakouri, Lithium recovery from desalination brines using specific ion-exchange resins, Desalination. 468 (2019) 114073. https://doi.org/10.1016/j.desal.2019.114073.

[5] Lithium Process Chemistry, Elsevier, 2016. https://doi.org/10.1016/C2013-0-19081-2.

[6] Y. Chen, Q. Tian, B. Chen, X. Shi, T. Liao, Preparation of lithium carbonate from spodumene by a sodium carbonate autoclave process, Hydrometallurgy. 109 (2011) 43-46. https://doi.org/10.1016/j.hydromet.2011.05.006.

[7] J.W. An, D.J. Kang, K.T. Tran, M.J. Kim, T. Lim, T. Tran, Recovery of lithium from Uyuni salar brine, Hydrometallurgy. 117-118 (2012) 64-70. https://doi.org/10.1016/j.hydromet.2012.02.008.

[8] P.K. Choubey, K.-S. Chung, M. Kim, J. Lee, R.R. Srivastava, Advance review on the exploitation of the prominent energy-storage element Lithium. Part II: From sea water and spent lithium ion batteries (LIBs), Minerals Engineering. 110 (2017) 104-121. https://doi.org/10.1016/j.mineng.2017.04.008. 
[9] J. Lee, E. Chung, Lithium recovery by solvent extraction from simulated shale gas produced water - Impact of organic compounds, Applied Geochemistry. 116 (2020) 104571. https://doi.org/10.1016/j.apgeochem.2020.104571.

[10] E. Jang, Y. Jang, E. Chung, Lithium recovery from shale gas produced water using solvent extraction, Applied Geochemistry. $78 \quad$ (2017) 343-350. https://doi.org/10.1016/j.apgeochem.2017.01.016.

[11] A. Kumar, H. Fukuda, T.A. Hatton, J.H. Lienhard, Lithium Recovery from Oil and Gas Produced Water: A Need for a Growing Energy Industry, ACS Energy Lett. 4 (2019) 1471-1474. https://doi.org/10.1021/acsenergylett.9b00779.

[12] J. Rydberg, M. Cox, C. Musikas, G.R. Choppin, Solvent extraction principles and practice, revised and expanded, 2004.

[13] Y. Sun, M. Zhu, Y. Yao, H. Wang, B. Tong, Z. Zhao, A novel approach for the selective extraction of $\mathrm{Li}+$ from the leaching solution of spent lithium-ion batteries using benzo15-crown-5 ether as extractant, Separation and Purification Technology. 237 (2020) 116325. https://doi.org/10.1016/j.seppur.2019.116325.

[14] L. Zhang, L. Li, H. Rui, D. Shi, X. Peng, L. Ji, X. Song, Lithium recovery from effluent of spent lithium battery recycling process using solvent extraction, Journal of Hazardous Materials. 398 (2020) 122840. https://doi.org/10.1016/j.jhazmat.2020.122840.

[15] Y. Song, L. He, Z. Zhao, X. Liu, Separation and recovery of lithium from Li3PO4 leaching liquor using solvent extraction with saponified D2EHPA, Separation and Purification Technology. 229 (2019) 115823. https://doi.org/10.1016/j.seppur.2019.115823.

[16] E.E. Çelebi, M.S. Öncel, M. Kobya, M. Bayramoğlu, Extraction of lithium from wastewaters using a synergistic solvent extraction system consisting of Mextral EOL and Cyanex 923, Hydrometallurgy. $185 \quad$ (2019) 46-54. https://doi.org/10.1016/j.hydromet.2019.01.016.

[17] L. Zhang, L. Li, D. Shi, X. Peng, F. Song, F. Nie, W. Han, Recovery of lithium from alkaline brine by solvent extraction with $\beta$-diketone, Hydrometallurgy. 175 (2018) 35-42. https://doi.org/10.1016/j.hydromet.2017.10.029.

[18] Kim, Young-Sang, In, Gyo, Choi, Jong-Moon, Chemical Equilibrium and Synergism for Solvent Extraction of Trace Lithium with Thenoyltrifluoroacetone in the Presence of Trioctylphosphine Oxide, Bulletin of the Korean Chemical Society. 24 (2003) 14951500. https://doi.org/10.5012/BKCS.2003.24.10.1495.

[19] R.E.C. Torrejos, G.M. Nisola, M.J. Park, A.B. Beltran, J.G. Seo, S.-P. Lee, W.-J. Chung, Liquid-liquid extraction of Li+ using mixed ion carrier system at room temperature ionic liquid, Desalination and Water Treatment. 53 (2015) 2774-2781. https://doi.org/10.1080/19443994.2014.931534.

[20] X. Sun, K.E. Waters, Development of Industrial Extractants into Functional Ionic Liquids for Environmentally Friendly Rare Earth Separation, ACS Sustainable Chem. Eng. 2 (2014) 1910-1917. https://doi.org/10.1021/sc500255n.

[21] L. Ji, L. Li, D. Shi, J. Li, Z. Liu, D. Xu, X. Song, Extraction equilibria of lithium with N, N bis(2-ethylhexyl)-3-oxobutanamide and tributyl phosphate in kerosene and $\mathrm{FeCl} 3$, 
Hydrometallurgy.

164

https://doi.org/10.1016/j.hydromet.2016.06.022.

[22] H. Su, Z. Li, J. Zhang, W. Liu, Z. Zhu, L. Wang, T. Qi, Combining Selective Extraction and Easy Stripping of Lithium Using a Ternary Synergistic Solvent Extraction System through Regulation of $\mathrm{Fe}^{3+}$ Coordination, ACS Sustainable Chem. Eng. 8 (2020) 1971-1979. https://doi.org/10.1021/acssuschemeng.9b06432.

[23] T. Nguyen, M. Lee, A Review on the Separation of Lithium Ion from Leach Liquors of Primary and Secondary Resources by Solvent Extraction with Commercial Extractants, Processes. 6 (2018) 55. https://doi.org/10.3390/pr6050055.

[24] C. Shi, Y. Jing, Y. Jia, Solvent extraction of lithium ions by tri-n-butyl phosphate using a room temperature ionic liquid, Journal of Molecular Liquids. 215 (2016) 640-646. https://doi.org/10.1016/j.molliq.2016.01.025.

[25] C. Shi, D. Duan, Y. Jia, Y. Jing, A highly efficient solvent system containing ionic liquid in tributyl phosphate for lithium ion extraction, Journal of Molecular Liquids. 200 (2014) 191-195. https://doi.org/10.1016/j.molliq.2014.10.004.

[26] G. Zante, A. Masmoudi, R. Barillon, D. Trébouet, M. Boltoeva, Separation of lithium, cobalt and nickel from spent lithium-ion batteries using TBP and imidazolium-based ionic liquids, Journal of Industrial and Engineering Chemistry. 82 (2020) 269-277. https://doi.org/10.1016/j.jiec.2019.10.023.

[27] C. Shi, Y. Jing, J. Xiao, X. Wang, Y. Yao, Y. Jia, Solvent extraction of lithium from aqueous solution using non-fluorinated functionalized ionic liquids as extraction agents, Separation and Purification Technology. 172 (2017) 473-479. https://doi.org/10.1016/j.seppur.2016.08.034.

[28] C. Shi, H. Li, B. Liu, Y. Qin, G. Song, Solvent extraction of lithium from aqueous solution using an ammonium ionic liquid, Journal of Molecular Liquids. 304 (2020) 112756. https://doi.org/10.1016/j.molliq.2020.112756.

[29] J.-P. Mikkola, P. Virtanen, R. Sjöholm, Aliquat $336^{\circledR}$-a versatile and affordable cation source for an entirely new family of hydrophobic ionic liquids, Green Chem. 8 (2006) 250. https://doi.org/10.1039/b512819f.

[30] M.T. Coll, A. Fortuny, A.M. Sastre, Boron reduction by supported liquid membranes using ALiCY and ALIDEC ionic liquids as carriers, Chemical Engineering Research and Design. 92 (2014) 758-763. https://doi.org/10.1016/j.cherd.2013.11.010.

[31] A. Fortuny, M.T. Coll, A.M. Sastre, Use of methyltrioctyl/decylammonium bis 2,4,4(trimethylpentyl)phosphinate ionic liquid (ALICY IL) on the boron extraction in chloride media, Separation and Purification Technology. 97 (2012) 137-141. https://doi.org/10.1016/j.seppur.2012.02.037.

[32] A.D. Sharma, N.D. Patil, A.W. Patwardhan, R.K. Moorthy, P.K. Ghosh, Synergistic interplay between D2EHPA and TBP towards the extraction of lithium using hollow fiber supported liquid membrane, Separation Science and Technology. 51 (2016) 2242-2254. https://doi.org/10.1080/01496395.2016.1202280. 
[33] R. Zheng, S. Bao, Y. Zhang, B. Chen, Synthesis of Di-(2-ethylhexyl) Phosphoric Acid (D2EHPA)-Tributyl Phosphate (TBP) Impregnated Resin and Application in Adsorption of Vanadium(IV), Minerals. 8 (2018) 206. https://doi.org/10.3390/min8050206.

[34] X. Sun, Y. Ji, F. Hu, B. He, J. Chen, D. Li, The inner synergistic effect of bifunctional ionic liquid extractant for solvent extraction, Talanta. 81 (2010) 1877-1883. https://doi.org/10.1016/j.talanta.2010.03.041.

[35] Y. Wang, Y. Wang, H. Zhou, F. Li, X. Sun, Extraction kinetics of mixed rare earth elements with bifunctional ionic liquid using a constant interfacial area cell, RSC Adv. 7 (2017) 39556-39563. https://doi.org/10.1039/C7RA07851J.

[36] C.J. Clarke, L. Bui-Le, P.J. Corbett, J.P. Hallett, Implications for Heavy Metal Extractions from Hyper Saline Brines with [NTf2] Ionic Liquids: Performance, Solubility, and Cost, Ind. Eng. Chem. Res. (2020) acs.iecr.9b04722. https://doi.org/10.1021/acs.iecr.9b04722. 
Solvent extraction of lithium from simulated shale gas produced water with a bifunctional ionic liquid

\section{Guillaume Zante ${ }^{\mathrm{a}, \mathrm{b},{ }^{*}, \text { Dominique Trébouet }}{ }^{\mathrm{a}}$, Maria Boltoeva ${ }^{\mathrm{a}}$}

a Université de Strasbourg, CNRS, IPHC UMR 7178, F-67000 Strasbourg, France

${ }^{\mathrm{b}}$ ADEME, 20 Avenue du Grésillé, 49004 Angers Cédex 01, France

*Corresponding author

E-mail address: guillaume.zante@etu.unistra.fr

\section{Graphical Abstract}

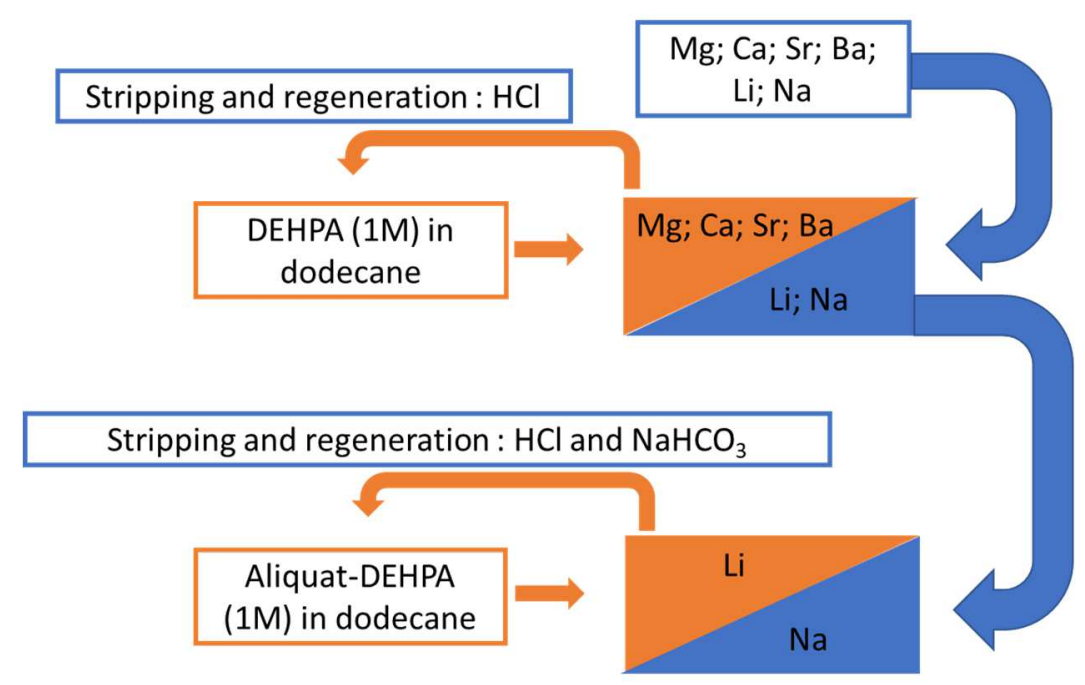

